\title{
Clinical Profile and Outcome among Infants of Diabetic Mothers Delivered at the Brooklyn Hospital Center
}

\author{
Uchendu O. Uchendu ${ }^{1,2, *}$, Patrick Leblanc ${ }^{1}$, Jude M. Thomas ${ }^{1}$, Ossama M. Maher ${ }^{1}$, \\ Yesenia Morales ${ }^{1}$ and Belen Fineza ${ }^{1}$
}

${ }^{1}$ Department of Pediatrics, The Brooklyn Hospital Center, Brooklyn New York, USA

${ }^{2}$ Department of Pediatrics, Pines Women and Children's Center, Caribou Maine, USA

\begin{abstract}
Background: Diabetes mellitus (DM) is the commonest complication of pregnancy, negatively impacting mothers and fetuses. Few studies suggest amelioration of negative outcomes of DM-associated pregnancies in recent years, due in part to improved care. But increasing prevalence of overweight in developed countries is also affecting many women of childbearing age with concomitant poor glycemic control especially in pregnancy. Hyperglycemia, even at sub-diabetic levels, is associated with increased risk of macrosomia and Cesarean section. There is evidence demonstrating that outcomes of DM-associated pregnancies are similar with those characterized by hyperglycemia of sub-diabetic levels. Perhaps, improvement of care for DM-associated pregnancies on one hand, and the impact of obesity epidemic may have changed the relative frequencies of negative outcomes typically reported for infants of diabetic mothers (IDMs) compared with controls.
\end{abstract}

Aims/Objective: We re-evaluated the relative frequencies of negative outcomes of pregnancies complicated by DM compared with non-diabetic pregnancies.

Method/Design: A retrospective cohort analysis was conducted.

Result: There were 50 diabetic and 83 non-diabetic mother-infant pairs. Mothers with DM-associated pregnancies had increased risk of delivery by C/Sxn, macrosomic babies, admission to NICU and prolonged hospitalization. Only IDMs had documented birth defects. Notable improvements over previous studies for IDMs include similar gestational ages at delivery and excellent APGAR scores in both groups.

Conclusion: IDMs still have higher frequencies of negative outcomes compared with controls but some improvements are noteworthy and should provide impetus for efforts at reducing prevalence of obesity while improving care for DMassociated pregnancies.

Keywords: Diabetes, Infant of diabetic mothers, pregnancy outcomes, newborn, hyperglycemia.

\section{INTRODUCTION}

Diabetes mellitus (DM) is one of the most common medical complications of pregnancy. A significant increase in preexisting diabetes during pregnancy has been observed in the USA between 1999 and 2005, rising from $10 \%$ to $21 \%$ [1]. Diabetes in pregnancy causes alterations from fertilization through all pregnancy period and even after its end. It predisposes the fetus to many alterations in organogenesis and growth [1]. Perinatal outcome is related to the onset and duration of glucose intolerance and to the severity of the disease. The White classification, which is based upon age of onset and duration of maternal diabetes and the presence of vasculopathy, is used to estimate prognosis and risk factors for fetal compromise $[2,3]$.

Few recent reports suggest a reduction in relative frequencies of some of the adverse outcomes associated with pregnancy complicated by DM. According to German population-based data on

*Address correspondence to this author at the Department of Pediatrics, Pines Women and Children's Center, Caribou Maine, USA; Tel: +12074981316; Fax: +12074981697; E-mail: u4chy2002@yahoo.co.uk
2,292,053 deliveries between 1987 and 2007 which assessed temporal trends for various pregnancy outcomes in consecutive 7 year intervals, the prevalence of stillbirths, premature delivery and macrosomia decreased over time in diabetic mothers as did the respective odds ratios [4]. So, they posited that although the risk of adverse pregnancy outcomes is still increased in diabetic mothers, considerable improvement has been achieved possibly due to improved diabetes care [4].

On another hand there is an increasing degree of overweight and obesity in developed countries including the US, with a 2009-2010 estimate that $35.7 \%$ of US adults were obese [5,6]. The average body mass index (BMI) is increasing in all categories, and women enter pregnancy at higher weights [7-10]. Obesity has several significant complications in pregnancy including impaired glucose tolerance and development of frank diabetes mellitus. Increased glucose levels, even below the threshold for gestational diabetes, for example, are associated with increase in the risk of macrosomia and Cesarean section as described by Sermer et al. [11] and by the 
Hyperglycemia and Adverse Pregnancy Outcomes (HAPO) Study [12]. Any degree of hyperglycemia on the fetal tissues stimulates insulin secretion that can cause hypertrophy of insulin-sensitive tissues such as adipose tissue, skeletal and myocardial muscle, hepatic tissues and even islets of Langerhans in the pancreas. This leads to accelerated fetal growth and eventually macrosomia.

We propose that better glycemic control in recent years and improved diabetic care may have had some impact on the relative frequencies of negative outcomes of pregnancies among women with diabetes compared with non-diabetic pregnancies. Conversely, the increasing prevalence of overweight and obesity in developed countries leading to concomitant poor glucose metabolism could amount to increased risk level for developing similar negative outcomes among infants of non-diabetic mothers. In this study we set out to evaluate if there is still any difference in frequencies of negative outcomes among infants of diabetic mothers and those of matched non-diabetic mothers born in our community in the past year.

\section{PATIENTS AND METHODOLOGY}

\section{Study Design}

We conducted a retrospective cohort analysis. The primary exposure of interest is being born by mother with diabetes in pregnancy. The exposed arm (primary study group) consisted of mother-infant dyads consisting of babies born to mothers with diabetes mellitus in the preceding 15-month period, whose data were complete within the newly-implemented electronic health records system at The Brooklyn Hospital Center (TBHC). Controls were babies born over the same time period to mothers without diabetes.

\section{Sampling Method}

Cases were identified from the electronic health records database of the Health Information Management (HIM) Department of TBHC using the ICD-code for 'infant of diabetic mothers' (ICD-775.0) or related codes. All babies born to mothers with a diagnosis of DM in pregnancy (infants of DM mothers, IDMs) were identified and included into the study. Controls (non-IDMs) were identified systematically from a list of all babies who were born over the same period as the cases (April 2011 to June 2012).

There were 2690 babies born over the given period. Of these 50 were IDMs and were all included in the analysis. After exclusion of the IDMs, we did a random selection of the non-IDMs taking the first and every consecutive $30^{\text {th }}$ baby on the list generated from the HIM department. From the electronic medical records of the babies we identified the mothers of each babies and using the search function, accessed the records of the mothers of the selected babies.

Cut off for various parameters of interest as our outcome measures were set according to already established and well-known standards in clinical practice. Term pregnancy is defined as pregnancy reaching at least 37 completed weeks. Macrosomia is defined as any baby weighing at least 4000 grams at birth. Polycythemia is taken as hematocrit of at least $65 \%$ or hemoglobin of at least $20 \mathrm{~g} / \mathrm{dl}$. Chemical hyperbilirubinemia in the neonatal period is taken as serum bilirubin above $5 \mathrm{mg} / \mathrm{dl}$. However, depending on other clinical and laboratory parameters treatment for hyperbilirubinemia in the neonatal period is usually based on a combination of factors and will be at variable levels.

All the electronic charts of the babies and their mothers were reviewed and appropriate data extracted using a study form (Appendix I).

The study was approved by the Institutional Review Board (IRB) of The Brooklyn Hospital Center. Strict guidelines regarding good clinical practice in research and Health Information Protection and Privacy Act (HIPPA) standards were met. Data extraction was done without any personal identifiers of patients.

\section{Statistical Analysis}

Data was entered and analyzed on Statistical Package for Social Sciences (SPSS) version 21.0. Data are presented in tabular formats. Categorical or discrete data were compared by chi-square testing of the distribution, while continuous variables were compared by performing the Student t-test. The contribution of various independent factors on the outcome measures was assessed by multivariate logistic regression analysis. The significance level was set at a $p$-value of $<0.05$.

\section{RESULTS}

One hundred and thirty three (133) mother-infant dyads were recruited into the study. Of these, 50 mothers had diabetes in pregnancy while 83 mothers were non-diabetics. The characteristics of the study participants (mothers and babies) according to history 
Table 1: Characteristics of Mothers and Babies in the Two Study Groups

\begin{tabular}{|c|c|c|c|c|c|c|c|}
\hline \multirow{3}{*}{ Characteristics } & \multicolumn{4}{|c|}{ Maternal History of Diabetes } & \multirow{3}{*}{ T-test } & \multirow{3}{*}{ p-value } & \multirow{3}{*}{$95 \% \mathrm{Cl}$} \\
\hline & \multicolumn{2}{|c|}{ Diabetic } & \multicolumn{2}{|c|}{ Non-diabetic } & & & \\
\hline & Freq. (\%) & Mean (SD) & Freq. (\%) & Mean (SD) & & & \\
\hline Maternal Age (yrs.) & 50 & $30.6(7.0)$ & 83 & $28.4(5.9)$ & 1.92 & 0.057 & $-0.06,4.46$ \\
\hline Weight (kg) & 50 & $104.42(21.5)$ & 83 & $79.84(13.9)$ & 7.75 & 0.000 & $18.31-30.85$ \\
\hline Height $(\mathrm{m})$ & 50 & $1.63(0.06)$ & 83 & $1.65(0.04)$ & -2.35 & 0.02 & $0.04-0.01$ \\
\hline BMI $\left(\mathrm{kg} / \mathrm{m}^{2}\right)$ & 50 & $39.10(8.02)$ & 83 & $29.05(5.00)$ & 8.56 & 0.000 & $7.72-12.37$ \\
\hline \multirow{2}{*}{$\begin{array}{c}\text { Mode of Delivery- } \\
---- \text { NSVD } \\
----C / S x n\end{array}$} & 13 & ---- & 61 & ---- & \multirow{2}{*}{$\begin{array}{c}x^{2}= \\
27.58\end{array}$} & \multirow[t]{2}{*}{0.000} & \\
\hline & 26 & --- & 22 & $-\cdots$ & & & \\
\hline Gestational Age (wks.) & 50 & $37.69( \pm 2.21)$ & 83 & $38.64(1.71)$ & & 0.008 & $-1.64--0.25$ \\
\hline \multirow{2}{*}{$\begin{array}{c}\text { Maturity-Preterm } \\
\text { Maturity- Term }\end{array}$} & 11 & ---- & 9 & --- & \multirow[t]{2}{*}{$\begin{array}{l}x^{2}= \\
3.09\end{array}$} & \multirow[t]{2}{*}{0.78} & \\
\hline & 37 & ---- & 71 & ---- & & & \\
\hline 1-Min Apgar $\geq 7$ & 46 & --- & 80 & $\begin{array}{ll}--- \\
--\end{array}$ & & & \\
\hline 5-Min Apgar $\geq 7$ & 47 & ---- & 83 & ---- & & & \\
\hline Birth Weight (g) & 50 & $\begin{array}{l}3621.10( \pm \\
760.50)\end{array}$ & 83 & $\begin{array}{l}3185.04 \\
(543.41)\end{array}$ & 3.84 & 0.000 & $211.75-660.37$ \\
\hline \multirow{2}{*}{$\begin{array}{c}\text { Macrosomia (wt. } \geq \\
\text { 4000g)---- Yes } \\
\text {--- No }\end{array}$} & 17 & ---- & 7 & ---- & & & \\
\hline & 33 & ---- & 76 & ---- & & & \\
\hline Birth Length (cm) & 50 & 49.85 (3.07) & 83 & $47.59(4.09)$ & 3.33 & 0.001 & $0.91-3.59$ \\
\hline \multirow{2}{*}{$\begin{array}{l}\text { Admission----NBN } \\
\text { Admission----NICU }\end{array}$} & 12 & --- & 73 & ---- & \multirow{2}{*}{$\begin{array}{l}x^{2}: 55 \\
32\end{array}$} & \multirow[t]{2}{*}{0.000} & \\
\hline & 38 & ---- & 10 & $-\cdots$ & & & \\
\hline \multirow{2}{*}{$\begin{array}{c}\text { Comorbidities -Yes } \\
\text {-No }\end{array}$} & 43 & --- & 11 & $-\cdots$ & \multirow{2}{*}{$\begin{array}{l}x^{2}= \\
70.74\end{array}$} & \multirow[t]{2}{*}{0.000} & \\
\hline & 7 & ---- & 72 & ---- & & & \\
\hline $\begin{array}{l}\text { Hyperbilirubinemia } \\
\text { requiring treatment }\end{array}$ & $19 / 50$ & ---- & $6 / 83$ & ---- & \multicolumn{3}{|c|}{ Relative Risk, $R R=5.3$} \\
\hline Hypoglycemia & $15 / 50$ & ---- & $0 / 83$ & ---- & \multicolumn{3}{|c|}{$\mathrm{RR}=5.3$} \\
\hline Polycythemia & $5 / 50$ & ---- & $0 / 83$ & ---- & \multicolumn{3}{|c|}{$\mathrm{RR}=5.3$} \\
\hline Hypocalcemia & $11 / 50$ & $-\cdots$ & $5 / 83$ & ---- & \multicolumn{3}{|c|}{$\mathrm{RR}=5.3$} \\
\hline Respiratory distress & $20 / 50$ & ---- & $7 / 83$ & ---- & \multicolumn{3}{|c|}{$\mathrm{RR}=5.3$} \\
\hline Sepsis & $21 / 50$ & --- & $9 / 83$ & --- & \multicolumn{3}{|c|}{$\mathrm{RR}=5.3$} \\
\hline $\begin{array}{c}\text { Duration of } \\
\text { Hospitalization (days) }\end{array}$ & 50 & $5.7(3.6)$ & 79 & $2.9(1.7)$ & 5.87 & 0.000 & $1.9-3.7$ \\
\hline
\end{tabular}

of DM in pregnancy are shown in Table 1. Of the 50 women with DM 36 (73.5\%) had gestational diabetes (GDM), while 13 had pre-gestational DM (PGDM); data was missing for 1 mother. Among 36 mothers diagnosed with GDM 18 were GDMA1 (diet-controlled) while 16 were GDMA2 (medication-controlled) by White's Classification. Classification for 2 mothers was unidentifiable.

\section{A. Maternal Age Statistics}

Mean maternal age was $29.0( \pm 6.4)$ years for entire study population. The minimum, maximum, median and modal ages were 17, 47, 29 and 25 years respectively.
Mothers with DM in pregnancy tended to be slightly older (30.6 \pm 7.0 years) than non-diabetic mothers (28.4 \pm 5.9 years) but there was no statistically significant difference between both groups. See Table 1.

\section{B. Maternal Anthropometric Parameters}

\section{Average Maternal Weights, Heights and BMI at Time of Delivery}

Mothers with diabetes in pregnancy had higher weight in comparison with non-diabetic mothers but the average heights of non-diabetic mothers (1.65 \pm 0.04 $\mathrm{m})$ were greater compared with diabetic mothers (1.63 $\pm 0.06 \mathrm{~m})$ and this was statistically significant. BMls 
were greater among diabetic mothers in comparison with controls.

\section{Pregnancy Outcomes}

\section{C. i. Mode of Delivery}

Sixty five $(65,48.9 \%)$ babies were born by vaginal delivery and $68(51.1 \%)$ by Caesarean section (C/S). More babies born by mothers with history of DM in pregnancy were delivered by $\mathrm{C} / \mathrm{S}(36 / 49 ; 73.5 \%)$. The relative risk for delivery by $\mathrm{C} / \mathrm{S}$ was 2.7 for mothers with DM in pregnancy compared with non-DM mothers; i.e. mothers with DM were almost 3 times more likely to deliver by $\mathrm{C} / \mathrm{S}$ when compared with controls.

\section{C. ii: Influence of Maternal Anthropometric Parameters on Mode of Delivery}

Overall, mothers who delivered by $\mathrm{C} / \mathrm{S}$ had higher mean weight and BMI but lower height at delivery when compared with those who had their babies by vaginal delivery. However, only the difference in mean weights between women who delivered by $\mathrm{C} / \mathrm{S}(92.75 \mathrm{~kg})$ and those who had normal vaginal delivery $(84.36 \mathrm{~kg})$ was statistically significant; $\{t$-test $=2.329, p=0.022 ; 95 \%$ $\mathrm{Cl}-15.52$ to -1.25$\}$.

We conducted a logistic regression analysis of the influence of various maternal factors including history of DM, maternal age and BMI on the mode of delivery. A tabular presentation of this relationship is shown in Table 2 . The odds of delivery by $\mathrm{C} / \mathrm{S}$ are expressed by this equation:

Log odd $[\mathrm{C} / \mathrm{Sxn}=1]=0.662+2.750$ [Maternal history of DM] -0.019 [Maternal age] -0.039 [Maternal BMI]

Even after controlling for the influence of age and $\mathrm{BMI}$, women with DM in pregnancy were still at higher risk of delivering by $\mathrm{C} / \mathrm{S}$. However, maternal age and $\mathrm{BMI}$ were not significant predictors of delivery by $\mathrm{C} / \mathrm{S}$ when the effect of history of DM in pregnancy was controlled. In fact IDMs are almost 16 times more likely to be delivered by $\mathrm{C} / \mathrm{S} x \mathrm{n}$ compared to non-IDMs after adjusting for effects of maternal ages and BMI at delivery.

\section{C. iii. Gestational Age (GA) at Delivery}

We evaluated duration of pregnancy in terms of maturity, a more useful outcome measure than absolute number of weeks of pregnancy. More babies of mothers with DM in pregnancy (11 in number) were born preterm ( $<37$ completed gestational weeks) compared with infants of non-diabetics (9) but this difference was not statistically significant $\left[x^{2}=3.09 ; p=\right.$ 0.78 ]. However, more IDMs were born at slightly lower GAs (37.69 \pm 2.21 weeks) compared with non-IDMs (38.64 \pm 1.71 weeks).

\section{Clinical Status of Babies}

\section{D. i. APGAR Scores}

Most babies (126/133, 94.7\%) had a 1-minute Apgar score of 7 or higher, and similarly so at 5 minute with $130 / 133(97.7 \%)$ having a score of at least 7 . No statistically significant difference was noted for Apgar scores at 1 and 5 minutes between both study groups.

\section{D. ii. Babies' Anthropometric Parameters}

Babies born to diabetic mothers were significantly heavier than controls; mean weights of 3621.10 \pm 760.50 grams and $3185.04 \pm 543.41$ respectively. Seventeen (17) IDMs were macrosomic compared with 7 non-IDMs and this was statistically significant $\left[x^{2}=\right.$ 13.79; $p=0.000$ ]. Likewise, IDMs were longer than the controls; lengths of $49.85 \pm 3.07 \mathrm{~cm}$ versus 47.59 $\pm 4.09 \mathrm{~cm}$ [t-test 3.337 ; p-value $0.001 ; 95 \% \mathrm{Cl}: 0.91$ to 3.59]. We did a multivariate logistic regression on possible determinants of babies' weights and even after adjusting for the effect of maternal age and BMI, IDMs were more likely to be macrosomic than nonIDMs. A tabular presentation of this relationship is shown in Table 3 and expressed in the equation below:

Log odd [Macrosomia $=1]=3.292-1.253$ [Maternal history of DM] + 0.033 [Maternal age] -0.062 [Maternal $\mathrm{BMI}]$

Table 2: Logistic Regression of Maternal History of DM, Maternal Age, BMI on Mode of Delivery

\begin{tabular}{|c|c|c|c|c|c|}
\hline $\begin{array}{c}\text { Maternal } \\
\text { Parameters }\end{array}$ & Beta & Std. Error. & $\begin{array}{c}\text { Wald chi-square } \\
\text { statistics }\end{array}$ & Significance level & $\begin{array}{c}\text { Exponential (B) i.e. } \\
\text { Odds Ratio }\end{array}$ \\
\hline \hline History of DM & 2.75 & .62 & 19.24 & 0.00 & 15.64 \\
\hline Age & -.01 & .03 & .33 & 0.56 & 0.98 \\
\hline BMI & -.03 & .03 & 1.21 & 0.27 & 0.96 \\
\hline Constant & .66 & 1.41 & .22 & 0.63 & 1.93 \\
\hline
\end{tabular}


Table 3: Logistic Regression of Maternal History of DM, Maternal Age and BMI on Birth Size of Babies

\begin{tabular}{|c|c|c|c|c|c|}
\hline $\begin{array}{c}\text { Maternal } \\
\text { Parameters }\end{array}$ & Beta & Std. Error. & $\begin{array}{c}\text { Wald chi-square } \\
\text { statistics }\end{array}$ & Significance level & $\begin{array}{c}\text { Exponential (B) i.e. } \\
\text { Odds Ratio }\end{array}$ \\
\hline \hline History of DM & -1.25 & .63 & 3.90 & 0.04 & 0.28 \\
\hline Age & .03 & .03 & .71 & 0.39 & 1.03 \\
\hline BMI & -.06 & .03 & 2.99 & 0.08 & 0.94 \\
\hline Constant & 3.29 & 1.59 & 4.24 & 0.03 & 26.88 \\
\hline
\end{tabular}

\section{E. Immediate Post-Natal Disposition}

Significantly higher numbers of IDMs were admitted to the neonatal intensive care unit (NICU) compared with controls. Relative risk for admission to the NICU for IDMs compared with non-IDMs was 6.3. That is, IDMs were 6 times more likely to be admitted to the NICU compared with non-IDMs. A multivariate logistic regression was done to adjust for the effect of maternal age and BMI, birth weight and maturity (term versus preterm) as possible predictors of disposition of care. This is represented by the expression below and shown in Table 4:

Log odd $[\mathrm{NICU}=1]=-2.359+4.097$ [Maternal history of $\mathrm{DM}$ ] + 4.622 [Maturity] - 0.070 [Maternal age] + 0.039 [Maternal BMI] $+0.034[$ Birth Wt] .

Being born by a woman with DM in pregnancy and prematurity appeared to be the only significant predictors of admission to the NICU. However, maternal age, BMI and baby's birth weight were not significant predictors of admissions to NICU even after controlling for maternal history of DM and prematurity.

\section{F. Birth Defects}

There were nine (9) babies with identified birth defects among the study population and these occurred only among IDMs. The incidence (proportion) of defects among IDMs was $9 / 50$ or $4.5 \%$. The documented defects included: Ventricular septal hypertrophy (4), hypertrophic cardiomyopathy (2), biventricular hypertrophy (1), septal defects (1), persistent ductus arteriosus (PDA) in combination with patent foramen ovale (PFO) and peripheral pulmonic stenosis (PPS) in 2 babies, microphthalmia (1), Erbs Palsy (1), Neonatal tooth (1). Of note, more than one defect was observed in some of the nine (9) babies who showed any defect.

\section{G. Comorbidities Developed (see Table 1)}

We considered hyperbilirubinemia, hypoglycemia, polycythemia, hypocalcemia, respiratory distress and sepsis as important comorbid conditions affecting outcome. Fifty-four (54/133, 41.2\%) babies developed co-morbid conditions among the study population. Of the 54 babies with observed co-morbid condition, 43 were IDMs while only 11 were born to mothers without DM. There is a significant association between development of co-morbidity and being born by mother with DM in pregnancy with a relative risk of 6.6 compared to non-IDMs.

\section{G. i. Hyperbilirubinemia}

Average total bilirubin levels were higher among IDMs compared with controls with statistically significant difference $(p<0.05)$. Forty $(40)$ out of 50 IDMs and 65/83 non-IDMs had total bilirubin (TB)

Table 4: Logistic Regression of Maternal History of DM, Maternal Age, BMI and Babies' Maturity and Weight on Immediate Disposition of Care

\begin{tabular}{|c|c|c|c|c|c|}
\hline $\begin{array}{c}\text { Independent } \\
\text { Parameters }\end{array}$ & Beta & Std. Error. & $\begin{array}{c}\text { Wald chi-square } \\
\text { statistics }\end{array}$ & Significance level & $\begin{array}{c}\text { Exponential (B) i.e. } \\
\text { Odds Ratio }\end{array}$ \\
\hline \hline $\begin{array}{c}\text { Maternal history of } \\
\text { DM }\end{array}$ & 4.09 & .85 & 22.80 & 0.00 & 60.18 \\
\hline Maturity of baby & 4.62 & 1.04 & 19.75 & 0.00 & 101.65 \\
\hline Maternal age & -.07 & .05 & 1.68 & 0.19 & .93 \\
\hline Maternal BMI & .03 & .04 & .64 & 0.42 & 0.96 \\
\hline Macrosomia & .03 & .80 & .00 & 0.26 & 1.04 \\
\hline Constant & -2.35 & 2.12 & 1.23 & & .09 \\
\hline
\end{tabular}


Table 5: Comparison of Mean Laboratory Parameters of IDMs and Controls

\begin{tabular}{|c|c|c|c|c|c|c|}
\hline Laboratory Parameters & $\begin{array}{l}\text { Maternal History of DM in } \\
\text { Pregnancy }\end{array}$ & No. & Mean (SD) & T-Test & P-Value & 95\% C.I. \\
\hline \multirow[t]{2}{*}{ Peak Bilirubin Level (mg/dl) } & Yes & 46 & $9.86(3.7)$ & \multirow[t]{2}{*}{3.39} & \multirow[t]{2}{*}{0.00} & \multirow[t]{2}{*}{$0.92-3.54$} \\
\hline & No & 57 & $7.61(3.0)$ & & & \\
\hline \multirow{2}{*}{$\begin{array}{l}\text { Blood Glucose 1-Hr Post- } \\
\text { partum (mg/dl) }\end{array}$} & Yes & 46 & $63.72(20.2)$ & \multirow[t]{2}{*}{-3.64} & \multirow[t]{2}{*}{0.00} & \multirow{2}{*}{$\begin{array}{l}7.27- \\
24.79\end{array}$} \\
\hline & No & 28 & $79.75(14.5)$ & & & \\
\hline \multirow[t]{2}{*}{ Hematocrit (\%) } & Yes & 41 & $52.59(2.3)$ & \multirow[t]{2}{*}{2.38} & \multirow[t]{2}{*}{0.02} & \multirow[t]{2}{*}{$0.66-7.58$} \\
\hline & No & 17 & $48.47(5.8)$ & & & \\
\hline \multirow[t]{2}{*}{ Serum Calcium (mg/dl) } & Yes & 26 & $8.90(1.3)$ & \multirow[t]{2}{*}{1.42} & 0.16 & \multirow[t]{2}{*}{$-0.28-1.61$} \\
\hline & No & 10 & $8.23(1.1)$ & & & \\
\hline
\end{tabular}

Key: *denotes statistically significant effect.

above cut-off values for definition of neonatal hyperbilirubinemia (TB $>5 \mathrm{mg} / \mathrm{dl}$ ). However, whereas 65 non-IDMs had TBs above $5 \mathrm{mg} / \mathrm{dl}$, considering the age of the babies and the level of the bilirubin only 6 of these required treatment for the hyperbilirubinemia. Among the IDMs, 19/40 with hyperbilirubinemia required treatment. Thus, IDMs were 5 times more likely to have hyperbilirubinemia requiring treatment. Most babies with hyperbilirubinemia requiring treatment received phototherapy; one case on each arm required IVIG for management of hyperbilirubinemia.

\section{G. ii. Hypoglycemia}

Mean blood glucose levels at birth or within first hour post-partum was higher among non-IDMs (79.7 $\mathrm{mg} / \mathrm{dl} \pm 14.5)$ than IDMs $(63.7 \mathrm{mg} / \mathrm{dl} \pm 20.2)$ with a statistically significant difference. More importantly, whereas there were 15 cases of hypoglycemia among IDMs none of the controls had a documented hypoglycemia.

\section{G. iii. Polycythemia}

Average hematocrit values were higher among IDMs $(52.6 \% \pm 6.0$ versus $48.5 \% \pm 5.0)$ and this was also statistically significantly different. Five (5) babies among the IDM group had hemoglobin levels greater than $20 \mathrm{gm} / \mathrm{dl}$ while none was observed among nonIDMs.

\section{G. iv. Hypocalcemia}

Mean serum calcium levels were slightly lower among non-IDMs $(8.23 \mathrm{mg} / \mathrm{dl} \pm 1.2)$ in comparison with IDMs $(8.90 \mathrm{mg} / \mathrm{dl} \pm 1.3)$ but this was not statistically significant $(p=0.164)$. However, 11 of the 50 IDMs and 5 out of 83 non-IDMs were documented to be hypocalcemic giving a relative risk of 3.6 for IDMs to develop hypocalcemia.

\section{G. v. Respiratory Distress}

There were twenty (20) babies among the IDMs who developed respiratory distress of various degrees compared with 6 of the 83 infants of non-diabetic mothers. IDMs were almost 5 times $(R R=4.7)$ more likely to have respiratory distress compared with nonIDMs.

\section{G. vi. Suspected/Proven Sepsis}

Significantly, more IDMs (21/50 IDMs) were suspected to have sepsis compared with $9 / 83$ nonIDMs, though most were never proven, microbiologically. The relative risk for IDM to develop signs and/or symptoms suggesting a diagnosis of sepsis was about 4 compared with non-IDMs.

\section{H. Total Duration of Hospital Stay (Table 1)}

Data regarding total duration of hospital stay was complete for 50 IDMs and 79 non-IDMs. Mean number of hospital days for IDMs was 5.7 days \pm 3.6 as against 2.9 days \pm 1.7 for non-IDMs. The difference was statistically significant $\{$ t-test $=5.87 ; p=0.000 ; 95 \% \mathrm{Cl}$ $=1.9-3.7\}$.

\section{DISCUSSION}

The average ages of both diabetic and non-diabetic mothers were comparable, with the former being slightly older. Women with DM had higher weights at time of delivery but were shorter, thus giving higher BMls for diabetic mothers. Our study showed that women with DM were 3 times more likely to deliver by $\mathrm{C} / \mathrm{S}$ compared with controls. Several studies have documented similar findings [13-18]. One primary reason for increased rate of delivery by $\mathrm{C} / \mathrm{S}$ is due to high rate of macrosomia among women with DM in 
pregnancy [19]. We lack data on the relative numbers of elective versus emergency $\mathrm{C} / \mathrm{S}$. Also we cannot say how many of those delivered by $\mathrm{C} / \mathrm{S}$ were done on account of fetal macrosomia. The various complications of pregnancies associated with DM including vascular changes of the placenta and poor fetal development may contribute to this outcome.

Women from both study groups who had higher weights and BMls at delivery were more likely to deliver by $\mathrm{C} / \mathrm{S}$. Considering the possible influence of weight and BMls along with increasing maternal age on mode of delivery we conducted a multivariate logistic regression for predictors of mode of delivery. Only maternal history of DM in pregnancy was a significant predictor. Thus, after controlling for the effect of maternal age and weight/BMI, IDMs were still about 16 times more likely to be born by $\mathrm{C} / \mathrm{S}$ compared with nonIDMs. Obesity as a contributor to delivery by $\mathrm{C} / \mathrm{S}$ has been well documented by Minsart et al. [17] in a population-based study in Belgium but this was not borne out in our study population. It may well be that the DM in pregnancy had an overshadowing effect on the impact of overweight and obesity on mode of delivery. A better assessment would have been the pre-conception weight or weight gain throughout pregnancy but these are often not available or only obtained by requesting women to recall their preconception weight at the time of initial booking for prenatal care, which introduces some errors.

Interestingly there was no difference in terms of the gestational age of babies at delivery. Average GAs of delivery was 37.69 weeks and 38.64 weeks for IDMs and non-IDMs respectively. Though women with DM in pregnancy had relatively more preterm deliveries (11 vs. 7) this was not significant. Many earlier studies have shown a tendency for IDMs to be delivered relatively earlier than those of none diabetic mothers $[18,19]$. Often it is thought to be due to the complications arising in pregnancies associated with diabetes which cause impairment in placental vascular function. Most mothers in our studies were of White Class A1 and A2. In fact most of these were GDMs. These are more likely to have milder disease and expectedly would not have developed the vascular complications that arise from long-standing DM. We believe this may mean overall less complicated pregnancies. On another hand the fact that even those with pre-gestational DM had only class $A 1$ and A2 DMs may allude to overall better controls and support our proposition that better control of DM would amount to less negative outcomes as demonstrated by most diabetic mothers being able to carry their pregnancies to term or near term. Furthermore, the increasing use of ultrasonographic fetal monitoring protocols to care for pregnant women with associated medical complications allows the obstetrician the ability to detect fetal complications that might prompt early delivery while also being able to allow those without any detected problems to proceed further. Thus, better care for pregnancies associated with DM would mean being able to have more mature babies born at term.

Another positive finding from our study population was the similarity of the APGAR scores of both groups at 1 and 5 minutes post-partum. Similar findings have been reported by Wahabi et al. [20] in Saudi Arabia. A significant number of our mothers were delivered by $\mathrm{C} / \mathrm{S}$, especially those with $\mathrm{DM}$ and according to a recent report it has been shown that delivery by $\mathrm{C} / \mathrm{S}$, especially if done electively, is associated with improved neonatal outcomes in terms of better APGAR scores at 5 minutes and lower rates of birth injuries [21].

IDMs were heavier than those born to non-diabetic mothers with overall mean weights of 3621 .1 grams and 3185.0 grams respectively. Seventeen of the IDMs were macrosomic (birth weight $\geq 4000$ grams) and there was a statistically significant difference between both study groups in terms of number of macrosomic babies. This is well documented in literature [20]. The primary reason proposed for macrosomia is the effect of uncontrolled maternal hyperglycemia which adversely influences fetal weight and growth. At moderately elevated levels of hyperglycemia macrosomia occurs, but at very high levels there is intrauterine growth restriction [21]. Other factors thought to contribute to development of macrosomia include maternal age over 30 years, prolonged pregnancy, multiparity and maternal obesity [22]. In our study even after adjusting for the effect of maternal age and mother's BMI IDMs were more likely to be macrosomic compared with nonIDMs. Large-for gestational-age babies, especially at the macrosomic range, are at increased risk of perinatal complications such as increased rate of $\mathrm{C} / \mathrm{S}$ deliveries, birth injuries and asphyxia, and perinatal mortality.

IDMs were 6 times more likely to be admitted to the NICU compared with non-IDMs. Pregnancies complicated by DM are associated with several complications (comorbidities) such as hypoglycemia, polycythemia, hypocalcemia and even development of respiratory distress. This was the case with our patient 
population and we believe these could have played a significant role in determining admission to the NICU. A multivariate logistic regression was done to adjust for the effect of maternal age and BMI, macrosomia (birth weight) and maturity (term versus preterm) as possible predictors of disposition of care. Maternal history of DM in pregnancy and prematurity appeared to be the only significant predictors of admission to the NICU. Given that there was no significant difference in terms of gestational age of delivery between our two study groups, we then think that our analysis only demonstrated maternal history of DM in pregnancy as one significant difference between the two arms in terms of admission to the NICU. As stated earlier more IDMs have increased risk of developing some metabolic complications which often require NICU care but we cannot say whether this increase in admission to the NICU reflects a precautionary tendency as a standard protocol of care due to the anticipated complications.

Nine babies had identifiable congenital birth defects among our study population, and this occurred only among the babies born to mothers with DM in pregnancy. We documented an incidence rate of $4.5 \%$ which falls within the reported range $(4-10$ times) from other studies. The pathogenesis of congenital malformations of all types in pregnant women with diabetes is very complex and has possibly a multifactorial origin [14,23]. A strong link between hyperglycemia and malformations has been established [25], but the precise mechanism by which it occurs has not been completely elucidated. It is supposed that hyperglycemia could cause damage to the developing yolk sac, an increased production and liberation of free oxygen radicals, deficiency of myoinositol and arachidonic acid and a disruption in signal transduction [24,26-29]. With increasing incidence of overweight and obesity in the general population and resultant metabolic derangement especially hyperglycemia [11, 12], though not to the degree that meets the criteria for a diagnosis of diabetes, we had proposed that perhaps we might be noticing some increase in the numbers of congenital defects compared to those in pregnancies complicated by DM. This is not borne out by our findings. We think that our study size may not be enough to detect this incidence in the normal population of women without DM in pregnancy.

There was a disproportionately higher number of IDMs presenting with comorbidities including hyperbilirubinemia, hypoglycemia, polycythemia, hypocalcemia and respiratory distress. Also more IDMs were investigated for sepsis. The occurrence of these metabolic complications among IDMs is well recognized $[18,20]$. Hyperbilirubinemia in IDMs is related to the development of chronic hyperinsulinism that leads to increased erythropoiesis and an accelerated hemolysis due to glycation process. Furthermore, higher incidence of prematurity with associated decreased hepatic conjugating ability and occurrence of polycythemia which increases the RBC load that are subject to hemolysis all contribute to the development of hyperbilirubinemia among IDMs. Of note is the fact that statistically significant more IDMs had hyperbilirubinemia requiring treatment.

The excess of insulin in the fetal circulation can delay pulmonary maturation associated with the low production of surfactant leading to the respiratory distress syndrome or hyaline membrane disease. Our population of IDMs had 5 times relative risk of developing respiratory distress which is comparable to the six-fold risk level reported by Kjos et al. [30]. Other factors may have contributed to this trend. More IDMs were born prematurely and also more IDMs were admitted to the NICU. Therefore, we believe that more IDMs were sicker and this may have also contributed to the development of these comorbidities. Even though more of the IDMs were evaluated for sepsis with presumptive treatment often commenced, most cases were never proven by microbiological evidence. Whereas the infants of non-diabetic mothers spent about 3 days on average in the hospital IDMs spent a significantly longer time $(5.7+/-3.6$ days) before discharge. Perhaps this is one unique outcome measure that we have evaluated which has been lacking in most prior studies. The reasons derive from the various issues that complicate pregnancies and deliveries by mothers with diabetes that amount to more extensive and expensive treatment modalities. And in our hospital setting discharges of mothers or babies are not affected by each other. The duration of stay of the babies reflect the decision of the physicians directly managing them; thus the differences between duration of hospitalization in both study arms would truly reflect issues arising principally from the medical conditions alone. One major concern regarding the management of IDMs then becomes the issue of the attendant cost arising from the level of care that is often required. Increased comorbidities imply increased laboratory investigations as well more expense in terms of time and treatment. Evaluating the cost implications of management of children born to mothers with DM 
would indeed demonstrate the added burden to the health care system and this perhaps might provide more impetus for optimizing the care of women with diabetes.

A very interesting trend is evident in our study population. Most of the women with DM in pregnancy had gestational DM without prior mention of being diabetic. And these were also of higher BMls. Thus, even though most of our 'diabetic' mothers may have started off as being non-diabetic, due to the metabolic burden of obesity and pregnancy many of them eventually developed gestational diabetes. Our assumption was that increasing overweight/obesity in our population may be shifting the trend of outcome of pregnancies for both diabetic and non-diabetic mothers. The observation in our study (which is retrospective) is that women who ended up having IDMs were predominantly obese, non-diabetic mothers at the outset. If this were a prospective cohort study perhaps these women developing GDM would have to be dropped out or crossed over to the other arm. We may have demonstrated the fact that obesity/ overweight is truly and significantly changing the trend with respect to creating more diabetic mothers in pregnancy who were hitherto non-diabetic. So in one sense we think that our otherwise non-diabetic mothers are actually ending up with babies who are similar to babies of mothers with pre-gestational diabetes, but this is only so because the metabolic effects of obesity have tipped them to levels similar to the pre-gestational diabetics. An interesting question to try to answer would be to know how many of these GDM that continue to have clinical symptoms of DM.

There are some evident weaknesses to our study. In attempting to have as much completed data as possible we limited our sampling frame to pregnancies and deliveries that had complete records in the newly implemented electronic health record system in our institution. This has affected the sample size of study. Also being a retrospective analysis we acknowledge that certain vital data were missed out. For instance we believe that weight gain throughout pregnancy or perhaps use of preconception weight would have been a better assessment of maternal weight but this could not be obtained in a retrospective study like ours. Overall we have demonstrated an approximation in the outcome of pregnancies of mothers with DM to those without it in terms of gestational age at delivery, excellent APGAR scores, but certain risk levels remain higher among women with pregnancies complicated by diabetes over normal pregnancies.

\section{AUTHORSHIP}

All the authors participated in the conception of the research. UOU designed the study tool and analyzed the data. UOU, JMT and MMO collected the data from the electronic health system. UOU wrote the article for publication which was then reviewed and approved by all the authors.

\section{CONFLICT OF INTEREST}

All the members of the research team declare no conflict of interest relevant to this study.

\section{SUPPLEMENTAL MATERIALS}

The supplemental proforma can be downloaded from the journal website along with the article.

\section{REFERENCES}

[1] Lawrence JM, Contreras R, Chen W, Sacks DA. Trends in the prevalence of preexisting diabetes and gestational diabetes mellitus among a racially/ethnically diverse population of pregnant women, 1999-2005. Diabetes Care 2008; 31(5): 899-904.

http://dx.doi.org/10.2337/dc07-2345

[2] Diamond, MP, Salyer, SL, Vaughn, WK, et al. Reassessment of White's classification and Pedersen's prognostically bad signs of diabetic pregnancies in insulin-dependent diabetic pregnancies. Am J Obstet Gynecol 1987; 156: 599-604. http://dx.doi.org/10.1016/0002-9378(87)90060-3

[3] Reece, EA, Sivan, E, Francis, G, Homko, CJ. Pregnancy outcomes among women with and without diabetic microvascular disease (White's classes $B$ to FR) versus nondiabetic controls. Am J Perinatol 1998; 15: 549-555. http://dx.doi.org/10.1055/s-2007-994059

[4] Beyerlein A, von Kries R, Hummel M, Lack N, Schiessl B, Giani $G$, Icks A. Improvement in pregnancy-related outcomes in the offspring of diabetic mothers in Bavaria, Germany, during 1987-2007. Diabet Med. 2010; 27(12): 1379-84. http://dx.doi.org/10.1111/j.1464-5491.2010.03109.x

[5] Flegal KM, Carroll MD, Ogden CL, Johnson CL. Prevalence and trends in obesity among US adults, 1999-2000. JAMA 2002; 288(14): 1723-7.

http://dx.doi.org/10.1001/jama.288.14.1723

[6] Ogden CL, Flegal KM, Carroll MD, Johnson CL. Prevalence and trends in overweight among US children and adolescents, 1999-2000. JAMA 2002; 288(14): 1728-32. http://dx.doi.org/10.1001/jama.288.14.1728

[7] Siega-Riz AM, Laraia B. The implications of maternal overweight and obesity on the course of pregnancy and birth outcomes. Matern Child Health J 2006; 10 (5 Suppl): S153-6. http://dx.doi.org/10.1007/s10995-006-0115-x

[8] Andreasen KR, Andersen ML, Schantz AL. Obesity and pregnancy. Acta Obstet Gynecol Scand 2004; 83(11): 102229

http://dx.doi.org/10.1080/j.0001-6349.2004.00624.x

[9] Guelinckx I, Devlieger R, Beckers K, Vansant G. Maternal obesity: pregnancy complications, gestational weight gain and nutrition. Obes Rev 2008; 9(2): 140-50. http://dx.doi.org/10.1111/j.1467-789X.2007.00464.x

[10] Heslehurst N, Simpson H, Ells LJ, Rankin J, Wilkinson J, Lang R, Brown TJ, Summerbell CD. The impact of maternal 
BMI status on pregnancy outcomes with immediate shortterm obstetric resource implications: a meta-analysis. Obes Rev 2008; 9(6): 635-83 http://dx.doi.org/10.1111/j.1467-789X.2008.00511.x

[11] Sermer M, Naylor CD, Gare DJ. Impact of increasing carbohydrate metabolism intolerance on maternal fetal outcomes in 3637 women without gestational diabetes: the Toronto tri-hospital gestational diabetes project. Am J Obstet Gynecol 1995; 173: 146-56. http://dx.doi.org/10.1016/0002-9378(95)90183-3

[12] Metzger BE, Lowe LP, Dyer AR, Trimble ER, Chaovarindr U, Coustan DR, et al. Hyperglycemia and adverse pregnancy outcomes. The HAPO Study cooperative research group. N Engl J Med 2008; 358(19): 1991-2002. http://dx.doi.org/10.1056/NEJMoa0707943

[13] Evers IM, de Valk HW, Visser GHA. Risk of complications of pregnancy in women with type 1 diabetes: nationwide prospective study in the Netherlands. BMJ 2004; 325: 91518. http://dx.doi.org/10.1136/bmj.38043.583160.EE

[14] Casson IF, Clarke CA, Howard CV, McKendrick O, Pennycook S, Pharoah PO, Platt MJ, Stanisstreet M, van Velszen $D$, Walkinshaw $S$. Outcomes of pregnancy in insulindependent diabetic women: results of a five year population cohort study. BMJ 1997; 315: 275-78. http://dx.doi.org/10.1136/bmj.315.7103.275

[15] Yang J, Cummings EA, O'Connell C, Jangaard K. Fetal and neonatal outcomes of diabetic pregnancies. Obstet Gynecol 2006; 108: 644-65.

http://dx.doi.org/10.1097/01.AOG.0000231688.08263.47

[16] Penney GC, Mair G, Pearson DW. Outcomes of pregnancies in women with type 1 diabetes in Scotland: a national population-based study. BJOG 2003; 110: 315-18. http://dx.doi.org/10.1046/j.1471-0528.2003.02067.x

[17] Minsart A, Buekens $P$, Spiegelaere MD, Englert $Y$. Neonatal outcomes in obese mothers: a population-based analysis. BMC Pregnancy and Childbirth 2013; 13: 36. http://dx.doi.org/10.1186/1471-2393-13-36

[18] Negrato CA, Mattar R, Gomes MB. Adverse pregnancy outcomes in women with diabetes. Diabetology \& Metabolic syndrome 2012; 4: 41 doi: 10.1186/1758-5996-4-41. http://dx.doi.org/10.1186/1758-5996-4-41

[19] El Mallah KO, Narchi H, Kulaylat NA, Shaban MS. Gestational and pregestational diabetes: comparison of maternal and fetal characteristics and outcome. Int $\mathrm{J}$ Gynaecol Obstet 1997; 58: 203-9. http://dx.doi.org/10.1016/S0020-7292(97)00084-2
[20] Wahabi HA, Esmaeil SA, Fayed A, Al-Shaikh G, Alzeidan RA. Pre-existing diabetes mellitus and adverse pregnancy outcomes. BMC Research Notes 2012; 5: 496. http://dx.doi.org/10.1186/1756-0500-5-496

[21] Rackham O, Paize F, Weindling AM. Cause of death in infants of women with pregestational diabetes mellitus and the relationship with glycemic control. Postgrad Med 2009; 121: 26-32. http://dx.doi.org/10.3810/pgm.2009.07.2026

[22] El FC, Mourali M, Ouerdiane N, Oueslati S, Hadj HA, Chaabene $\mathrm{M}$, et al. Maternal and fetal outcomes of large fetus delivery: A comparative study. Tunis Med 2011; 89: 553-6.

[23] Hawthorne G, Robson S, Ryall EA, Sen D, Roberts SH Ward Platt MP. Prospective population based survey of outcome of pregnancy in diabetic women: results of the Northern Diabetic Pregnancy Audit, 1994. BMJ 1997; 315: 279-81.

http://dx.doi.org/10.1136/bmj.315.7103.279

[24] Reece EA, Homko C. Why do diabetic women deliver malformed infants? Clin Obstet Gynecol 2000; 43: 32-45. http://dx.doi.org/10.1097/00003081-200003000-00004

[25] Jovanovic L, Pettitt DJ: Gestational diabetes mellitus. JAMA 2001; 286: 2516-18.

http://dx.doi.org/10.1001/jama.286.20.2516

[26] Hod M. Advances in the understanding of diabetic embryopathy: Signal transduction. Early Pregnancy 1996; 2: 121-28.

[27] Sadler TW, Hunter ES, Wynn RE, Phillips LS. Evidence for multifactorial origin of diabetes-induced embryopathies. Diabetes 1989; 38: 70-4. http://dx.doi.org/10.2337/diab.38.1.70

[28] Eriksson UJ, Borg LAH. Diabetes and embryonic malformations: role of substrate-induced free oxygen radical production for dysmorphogenesis in cultured rat embryos. Diabetes 1993; 42: 411-19.

http://dx.doi.org/10.2337/diab.42.3.411

[29] Reece EA, Homko CJ, Wu YK. Multifactorial basis of the syndrome of diabetic embryopathy. Teratology 1997; 54 171-82.

http://dx.doi.org/10.1002/(SICI)10969926(199610)54:4<171::AID-TERA1>3.0.CO;2-4

[30] Kjos SL, Walther F. Prevalence and etiology of respiratory distress in infants of diabetic mothers: predictive value of lung maturation tests. Am. J Obstet Gynecol 1990; 163(3): 898-903. http://dx.doi.org/10.1016/0002-9378(90)91092-Q

Received on 05-02-2014

Accepted on 26-02-2014

Published on 10-03-2014

http://dx.doi.org/10.6000/1929-4247.2014.03.01.3

(C) 2014 Uchendu et al.; Licensee Lifescience Global.

This is an open access article licensed under the terms of the Creative Commons Attribution Non-Commercial License (http://creativecommons.org/licenses/by-nc/3.0/) which permits unrestricted, non-commercial use, distribution and reproduction in any medium, provided the work is properly cited. 